\title{
ESTIMATES FOR THE CORONA THEOREM ON $H_{\mathbb{I}}^{\infty}(\mathbb{D})$
}

\author{
DEBENDRA P. BANJADE
}

\begin{abstract}
Let $\mathbb{I}$ be a proper ideal of $H^{\infty}(\mathbb{D})$. We prove the corona theorem for infinitely many generators in the algebra $H_{\mathbb{I}}^{\infty}(\mathbb{D})$. This extends the finite corona results of Mortini, Sasane, and Wick [8]. We also provide the estimates for corona solutions. Moreover, we prove a generalized Wolff's Ideal Theorem for this sub-algebra.
\end{abstract}

Mathematics subject classification (2010): Primary 30H50, Secondary, 30H80, 46J20. Keywords and phrases: Corona theorem, Wolff's theorem, $H^{\infty}(\mathbb{D})$, ideals.

\section{REFERENCES}

[1] L. CARLESON, Interpolation by bounded analytic functions and the corona problem, Annals of Math. 76 (1962), 547-559.

[2] U. CEgRell, A generalization of the corona theorem in the unit disc, Math. Z. 203 (1990), 255-261

[3] U. Cegrell, Generalizations of the corona theorem in the unit disc, Proc. Royal Irish Acad. 94 (1994), 25-30.

[4] K. R. Davidson, V. I. Paulsen, and M. Ragupathi, And D. Singh, A constrained NevanlinnaPick theorem, Indiana Math. J. 58 (2009), no. 2, 709-732.

[5] J. B. GARnetT, Bounded Analytic Functions, Academic Press, (2007).

[6] P. Gorkin, R. Mortini, AND A. Nicolau, The generalized corona theorem, Math. Annalen 301 (1995), 135-154.

[7] R. Mortini, Generating sets for Ideals of finite type in $H^{\infty}$, Bull. Sci. Math. 136 (2012), 687-708.

[8] R. Mortini, A. SASANE, AND B. Wick, The corona theorem and stable rank for $\mathbb{C}+B H^{\infty}(\mathbb{D})$, Houston J. Math. 36 (2010), no. 1, 289-302.

[9] N. K. NiKOLSKI, Treatise on the Shift Operator, Springer-Verlag, New York (1985).

[10] M. Ragupathi, Nevanlinna-Pick interpolation for $\mathbb{C}+B H^{\infty}(\mathbb{D})$, Integral Equa. Oper. Theory 63 (2009), 103-125.

[11] J. PAU, On a generalized corona problem on the unit disc, Proc. Amer. Math. Soc. 133 (2004) no. 1, $167-174$.

[12] K. V. R. RAO, On a generalized corona problem, J. Analyse Math. 18 (1967), 277-278.

[13] M. V. Renteln, Finitely generated ideals in the Banach algebra $H^{\infty}$, Collectanea Mathematica 26 (1975), 3-14.

[14] M. Rosenblum, A corona theorem for countably many functions, Integral Equa. Oper. Theory 3 (1980), no. 1, 125-137.

[15] J. RYLE, A corona theorem for certain subalgebras of $H^{\infty}(\mathbb{D})$, Dissertation, The University of Alabama, (2009).

[16] J. RYle And T. TREnT, A corona theorem for certain subalgebras of $H^{\infty}(\mathbb{D})$, Houston J. Math 37 (2011), no. 4, 1211-1226.

[17] S. SCheinBerg, Cluster sets and corona theorems in Banach spaces of analytic functions, Lecture Notes in Mathematics, Springer, New York, 1976.

[18] J. RYle And T. TRENT, A corona theorem for certain subalgebras of $H^{\infty}(\mathbb{D}) I I$, Houston J. Math 38 (2012), no. 4, 1277-1295.

[19] S. SCHEInBERG, Cluster sets and corona theorems in Banach spaces of analytic functions, Lecture Notes in Mathematics, Springer, New York, 1976. 
[20] V. A. Tolokonnikov, The corona theorem in algebras of smooth functions, Translations (American Mathematical Society), 149 (1991) no. 2, 61-95.

[21] S. R. TREIL, Estimates in the corona theorem and ideals of $H^{\circ}$ : A problem of T. Wolff, J. Anal. Math 87 (2002), 481-495.

[22] S. R. TREIL, The problem of ideals of $H^{\infty}(\mathbb{D})$ : Beyond the exponent $\frac{3}{2}$, J. Fun. Anal. 253 (2007), 220-240.

[23] T. TRent, An estimate for ideals in $H^{\infty}(\mathbb{D})$, Integr. Equat. Oper. Th. 53 (2005), 573-587.

[24] T. TRENT, An $H^{2}$ corona theorem on the bidisk for infinitely many functions, Linear Alg. and App. 379 (2004), 213-227.

[25] T. TRent, A note on multiplication algebras on reproducing kernel Hilbert spaces, Proc. Amer. Math. Soc. 136 (2008), 2835-2838.

[26] A. UChiYAma, Corona theorems for countably many functions and estimates for their solutions, preprint, UCLA, 1980.

[27] T. WolfF, A refinement of the corona theorem, in Linear and Complex Analysis Problem Book, by V. P. Havin, S. V. Hruscev, and N. K. Nikolski (eds.), Springer-Verlag, Berlin (1984). 